\title{
Asian Society of Gynecologic Oncology International Workshop 2014
}

\author{
Jeong-Yeol Park', Hextan Yuen Sheung Ngan², Won Park', Zeyi Cao ${ }^{4}$, Xiaohua Wu ${ }^{5}$, Woong Ju ${ }^{6}$, Hyun Hoon Chung ${ }^{7}$, \\ Suk-Joon Chang ${ }^{8}$, Sang-Yoon Park ${ }^{9}$, Sang-Young Ryu ${ }^{10}$, Jae-Hoon Kim ${ }^{11}$, Chi-Heum Cho ${ }^{12}$, Keun Ho Lee ${ }^{13}$, \\ Jeong-Won Lee ${ }^{14}$, Suresh Kumarasamy ${ }^{15}$, Jae-Weon Kim ${ }^{7}$, Sarikapan Wilailak ${ }^{16}$, Byoung-Gie Kim ${ }^{14}$, Dae-Yeon Kim ${ }^{1}$, \\ Ikuo Konishi $^{17}$, Jae-Kwan Lee ${ }^{18}$, Kung-Liahng Wang ${ }^{19,20}$, Joo-Hyun Nam ${ }^{1}$ \\ 'Department of Obstetrics and Gynecology, Asan Medical Center, University of Ulsan College of Medicine, Seoul, Korea; \\ ${ }^{2}$ Department of Obstetrics and Gynecology, The University of Hong Kong, Queen Mary Hospital, Hong Kong; ${ }^{3}$ Department of \\ Radiation Oncology, Samsung Medical Center, Sungkyunkwan University School of Medicine, Seoul, Korea; ${ }^{4} \mathrm{Obstetrics}$ and \\ Gynecology Center, Tsinghua University School of Medicine, Beijing; ${ }^{5}$ Department of Gynecologic Oncology, Fudan University \\ Shanghai Cancer Center, Shanghai, China; ${ }^{6}$ Department of Obstetrics and Gynecology, Ewha Womans University School of \\ Medicine, Seoul; ${ }^{7}$ Department of Obstetrics and Gynecology, Seoul National University College of Medicine, Seoul; ${ }^{8}$ Gynecologic \\ Cancer Center, Department of Obstetrics and Gynecology, Ajou University School of Medicine, Suwon; ${ }^{9}$ Center for Uterine \\ Cancer, Research Institute and Hospital, National Cancer Center, Goyang; ${ }^{10}$ Department of Obstetrics and Gynecology, Korea \\ Cancer Center Hospital, Korea Institute of Radiological \& Medical Sciences, Seoul; "'Department of Obstetrics and Gynecology, \\ Gangnam Severance Hospital, Yonsei University College of Medicine, Seoul; ${ }^{12}$ Department of Obstetrics and Gynecology, \\ Keimyung University School of Medicine, Daegu; ${ }^{13}$ Department of Obstetrics and Gynecology, The Catholic University of Korea \\ College of Medicine, Seoul; ${ }^{14}$ Department of Obstetrics and Gynecology, Samsung Medical Center, Sungkyunkwan University \\ School of Medicine, Seoul, Korea; ${ }^{15}$ Gleneagles Penang, Penang Medical College, Penang, Malaysia; ${ }^{16}$ Department of Obstetrics \\ and Gynecology, Ramathibodi Hospital, Mahidol University Faculty of Medicine, Bangkok, Thailand; ${ }^{17}$ Department of Gynecology \\ and Obstetrics, Kyoto University Graduate School of Medicine, Kyoto, Japan; ${ }^{18}$ Department of Obstetrics and Gynecology, Korea \\ University Medical Center, Seoul, Korea; ${ }^{19}$ Department of Obstetrics and Gynecology, Mackay Memorial Hospital, Mackay Medical \\ College, Taipei; ${ }^{20}$ Department of Nursing, Mackay Junior College of Medicine Nursing, and Management, Taipei, Taiwan
}

\begin{abstract}
The Asian Society of Gynecologic Oncology International Workshop 2014 on gynecologic oncology was held in Asan Medical Center, Seoul, Korea on the 23rd to 24th August 2014. A total of 179 participants from 17 countries participated in the workshop, and the up-to-date findings on the management of gynecologic cancers were presented and discussed. This meeting focused on the new trends in the management of cervical cancer, fertility-sparing management of gynecologic cancers, surgical management of gynecologic cancers, and recent advances in translational research on gynecologic cancers.
\end{abstract}

Keywords: Endometrial Neoplasms; Fertility Preservation; Laparoscopy; Ovarian Neoplasms; Uterine Cervical Neoplasms

\section{INTRODUCTION}

The Asian Society of Gynecologic Oncology International Workshop 2014 on gynecologic oncology was held in Asan

Received Dec 12, 2014, Accepted Dec 13, 2014

Correspondence to Joo-Hyun Nam

Department of Obstetrics and Gynecology, Asan Medical Center, University of Ulsan College of Medicine, 88 Olympic-ro 43-gil, Songpa-gu, Seoul 138736, Korea.E-mail:jhnam@amc.seoul.kr
Medical Center, Seoul, Korea on the 23rd to 24th August 2014. The workshop was aimed at enhancing the knowledge of Asian young doctors on gynecologic oncology, sharing up-to-date knowledge about the management and care of gynecologic cancer patients in Asian countries, and renewing old acquaintances and making new ones. A total of 179 participants from 17 countries (Korea, Japan, China, Indonesia, Nepal, India, Malaysia, Myanmar, Thailand, Zimbabwe, Philippines, Mongolia, Hong Kong, Singapore, Sri Lanka, Taiwan, and USA) participated in the workshop, which comprised 
27 lectures divided into seven sessions and two seminars (Supplementary 1-3).

\section{SESSION 1. NEW TRENDS IN THE MANAGEMENT OF CERVICAL CANCER}

\section{Updates on cervical cancer prevention and control}

Cervical cancer is still the most common gynecologic cancer in the world despite the adoption of vaccination against human papilloma virus (HPV) (primary prevention) and a nationwide screening program (secondary prevention) for cervical cancer in many countries. Cervical cancer can be prevented effectively by HPV vaccines, but the global implementation of HPV vaccines is still ongoing. Hextan YS Ngan suggested several reasons for this, including the cost of $H P V$ vaccines, doubts about the efficacy of HPV vaccines, and the length of protection. Although population vaccination in several countries has lowered the incidence of abnormal cervical cytology, the need for colposcopy, and the treatment for high-grade cervical intraepithelial neoplasia [1], screening is still recommended after vaccination and this adds to the cost. Recent clinical trials have suggested that two doses instead of three doses of the vaccine would reduce cost $[2,3]$. Newly developed nanovalent vaccines may prevent up to $90 \%$ of high-grade cervical intraepithelial neoplasia and thus it is probably acceptable not to continue screening. For cervical cancer screening, the high-risk HPV test is more sensitive than conventional cytology screening and was recently approved as a primary screening tool [4]. The high negative predictive value of the high-risk HPV test can lengthen the intervals between screenings; however, because the management of cases with a positive HPV test result has not been implemented, a second triage to reduce unnecessary colposcopy and treatment is required.

\section{Tailored radiation therapy: intensity-modulated radiotherapy/proton therapy}

Radiotherapy has been an important part of the management of gynecologic cancers for a long time and reduces the loco-regional failure rate and improves survival outcome. New techniques for delivering radiation to targets, including intensity-modulated radiotherapy (IMRT) and proton therapy, for the management of gynecologic cancers were reviewed and discussed in the session. IMRT is better at reducing the delivery of radiation to adjacent normal tissue, such as rectum, bladder, and small bowel, and results in the delivery of a higher tumor dose compared with conventional or 3-dimensional conformal radiotherapy. It also can probably provide benefits in terms of increased tumor control and decreased toxicity to normal tissues; however, the study of the clinical significance of IMRT in the management of gynecologic cancers has been limited in several reports [5-9]. A randomized phase 3 clinical trial is ongoing to compare standard radiotherapy to IMRT for the postoperative treatment of endometrial and cervical cancer (RTOG protocol 1203). Proton therapy completes energy delivery at a defined depth and has no exit energy after the Bragg peak. It can decrease the irradiated volume and reduce the dose to adjacent normal tissues beyond that achievable by IMRT; however, there is no clinical data to confirm that proton therapy reduces normal tissue toxicity. Photon therapy still remains mostly an investigational tool for the management of gynecologic cancers. Prospective clinical trials are required to evaluate the efficacy of IMRT and proton therapy in the management of gynecologic cancers.

\section{The evolution of treatment methods for cervical cancer in China}

The recent evolution in methods for the treatment of cervical cancer was presented by Zeyi Cao. In the past, radiotherapy was the mainstay of cervical cancer treatment, but the use of surgery, IMRT, concurrent chemoradiation therapy, and neoadjuvant chemotherapy has increased. During the last three decades, the proportion of young patients with cervical cancer has increased from 10\% to 40\%. From the perspective of quality of life, surgery has now become the primary treatment modality in approximately $90 \%$ of patients with cervical cancer. Dr. Cao reported that new techniques to treat cervical cancer would probably be introduced in the near future, including personalized function-sparing surgery and minimally invasive surgery (laparoscopic and robotic surgery).

\section{SESSION 2. SPECIAL ISSUES 1: PRESERVING FERTILITY IN GYNECOLOGIC CANCER PATIENTS}

Young women with early gynecologic cancers have excellent survival outcomes when treated with current treatment modalities; however, quality of life is as important as survival outcome for these patients. Recently, increasing interest has been given to improving the quality of life of gynecologic cancer patients. Fertility preservation is one of the most important quality-of-life issues in young women with early gynecologic cancers. In this session, up-to-date findings regarding fertilitypreserving management for early cervical, endometrial, and ovarian cancer were thoroughly reviewed and discussed. 


\section{Fertility preservation in cervical cancer}

Fertility-preserving radical trachelectomy has been accepted as a reasonable alternative treatment for young women with early cervical cancer who wish to preserve their fertility. Currently, several types of surgical approaches for radical trachelectomy are used in real practice, including vaginal, abdominal, laparoscopic, and robotic radical trachelectomy. The use of vaginal radical trachelectomy is limited to small cervical cancers with a tumor size $<2 \mathrm{~cm}$ because the recurrence rate is significantly higher when the tumor size is $>2 \mathrm{~cm}[10,11]$; however, because wider extirpation of parametrial tissue has become possible using other surgical approaches including abdominal, laparoscopic, and robotic radial trachelectomy [12], recent investigators have suggested that radical trachelectomy be extended to selected patients with a tumor size $>2$ and $<4 \mathrm{~cm}$ [13-15].

\section{Fertility preservation in endometrial cancer}

Fertility-preserving management using oral progestin is regarded as a safe alternative treatment for selected young women with early endometrial cancer who want to preserve their fertility $[16,17]$. Indication of this treatment is now limited to well-differentiated, endometrioid-type, endometrial cancers confined to the endometrium $[16,17]$. Definitive surgical management should be considered after the completion of family planning because of the high rate of recurrence $[16,17]$. Recent reports have pointed to promising pregnancy outcomes $[16,18]$ and the safety of the treatment for more advanced and recurrent disease [19,20]; however, further studies will be required to define the optimal agents and dosing schedule, as well as to determine the safety of this treatment for more advanced disease and recurrent disease.

\section{Fertility preservation in ovarian cancer}

Fertility-preserving surgery is a well-established treatment modality in young women with borderline ovarian tumors and malignant ovarian germ cell tumors; however, the acceptance of fertility-preserving surgery for the management of invasive epithelial ovarian cancer occurred later than its acceptance for the management of borderline ovarian tumors and malignant ovarian germ cell tumors. Although there has never been a prospective trial to evaluate the role of fertilitysparing surgery in invasive epithelial ovarian cancer, currently available evidence suggests that fertility-sparing surgery is safe in selected young women with early epithelial ovarian cancer. It can be safely performed on patients with non-clear cell histology, stage IA to IC (grade 1 to 2) disease, and clear cell histology, stage IA disease [21,22].

\section{SESSION 3. SURGERY FOR GYNECOLOGIC CANCER 1}

Recent advances in surgical management of gynecologic cancers were reviewed and discussed in Session 3 and 6. This session focused on the role of sentinel lymph node mapping and cytoreductive surgery for invasive epithelial ovarian cancer, and pelvic exenteration and laterally extended endopelvic resection (LEER) for recurrent cervical cancer.

\section{Sentinel lymph node mapping in endometrial cancer}

The concept of the sentinel lymph node has been developed for the surgical management of several types of cancers. In early endometrial cancer, the role of pelvic lymph node dissection is limited to a staging role because two randomized clinical trials failed to show the survival benefit of pelvic lymph node dissection [23]. Therefore, accurate staging of lymph node status while minimizing complications associated with pelvic lymph node dissection is important; thus the sentinel lymph node concept is being evaluated. Several types of sentinel lymph node mapping techniques were reviewed in this lecture. Although there exists insufficient evidence to support their large-scale deployment and significant disagreement regarding their use, they may be considered in selected patients with early endometrial cancer. Increasing surgeon exposure to, and experience with, these techniques will be important for their future success. Future prospective studies should try to confirm the role of sentinel lymph node mapping in early endometrial cancer.

\section{Cytoreductive surgery in ovarian cancer: pelvis and upper abdomen}

Surgery has an important role to play in the management of all epithelial ovarian cancers. The size of a residual tumor after cytoreductive surgery is the single most important prognostic factor and the only prognostic factor that the surgeon can modify. Surgical techniques for optimal cytoreduction of pelvic disease and abdominal disease were reviewed and shown in surgical videos in two lectures. Recently, the goal of optimal cytoreduction has changed from that of obtaining a level of small residual disease $<1 \mathrm{~cm}$ to that of obtaining no grossly visible tumor, because many studies have confirmed the further survival benefit of complete cytoduction over that of leaving a small residual disease $<1 \mathrm{~cm}$ [24].

\section{Pelvic exenteration and LEER for recurrent cervical cancer}

Pelvic exenteration is sometimes the last chance of obtaining a cure for recurrent cervical cancer in the irradiated pelvis. If the tumor is located in the lateral side of the pelvis, LEER can be used as an alternative surgical approach. The surgical 
techniques and outcomes of pelvic exenteration and LEER in recurrent cervical cancer were reviewed in this lecture. The mortality rate has decreased continuously from $25 \%$ to less than $5 \%$, and the 5 -year survival rate has continuously improved from $22 \%$ to more than $50 \%$ [25]. Considering the absence of other curable treatment modalities for recurrent cervical cancer, these outcomes are very promising.

\section{SESSION 4. RECENT ADVANCES IN TRANSLATIONAL RESEARCH}

This session focused on the recent advances in translational research for gynecologic cancers, including advances in the use of biomarkers, The Cancer Genome Atlas (TCGA), microRNAs, and patient-derived tumor xenograft (AVATAR) models.

\section{Biomarkers for epithelial ovarian cancer}

Research into new biomarkers for the screening, diagnosis, disease monitoring, and surveillance of ovarian cancer has drawn increasing interest from doctors and surgeons who treat this disease. Although numerous studies have been performed in this direction, obtaining an early diagnosis of ovarian cancer is still challenging. The use of multiple serum markers for early diagnosis has not yet been established. Recently, two algorithms to estimate the risk of ovarian cancer in women with a pelvic mass have been approved (ROMA and OVA1). CA-125 is still a useful marker for prognosis and disease monitoring.

\section{The cancer genome atlas: TCGA data mining}

TCGA is a large-scale collaborative effort to understand the molecular basis of cancer through the application of genome analysis technologies, including, but not limited to, identifying mutations in DNA sequences, copy number variation, and alterations in methylation status. Considerable research has been expended in identifying the genomic changes in more than 20 different types of human cancer, including gynecologic cancers, and analyzing hundreds of samples for each type of cancer. By comparing the DNA in samples of normal tissue with those in cancer tissues taken from the same patient, researchers have identified changes specific to particular cancers. By connecting specific genomic changes with specific outcomes, researchers will be able to develop more effective, individualized ways of helping each cancer patient.

\section{MicroRNA strategy in ovarian cancer}

MicroRNAs are a class of small non-coding RNAs that regulate the translation of mRNAs by inhibiting translation. Abnormal expression of microRNA has been observed in gynecologic malignancies including ovarian cancer. Several microRNA profiling studies have identified the changes in miRNA patterns that take place during ovarian cancer development and some of them may represent targets for therapy. In addition, some of the microRNA patterns may have prognostic significance. A better understanding of microRNA expression may provide a new way for the detection, diagnosis, and treatment of ovarian cancer.

\section{Patient-derived tumor xenograft model (AVATAR) model for gynecologic cancer}

A patient-derived tumor xenograft model is built by transplanting the patient's tumor tissue into an immunodeficient mouse. In this lecture, the applications of patient-derived tumor xenografts in gynecologic cancer research were presented. This model better preserves the morphology and gene expression of the patient's tumor than conventional xenografts established using cancer cell lines. The patient-derived tumor xenograft model offers a powerful tool for studying tumor biology and a good platform for the establishment of personalized medicine for patients with gynecologic cancers.

\section{SESSION 5. SPECIAL ISSUES 2: UPDATES ON THE MANAGEMENT OF GYNECOLOGIC CANCERS}

\section{Current practice for selecting and testing ovarian cancer patients for BRCA mutations}

Hereditary ovarian cancer accounts for $5 \%$ to $10 \%$ of all ovarian cancers, and germline mutations in BRCA1 and BRCA2 are fundamental defects underlying hereditary ovarian cancer, where they account for approximately $10 \%$ of all cases. A PARP inhibitor has been reported to be effective in patients with recurrent epithelial ovarian cancer and germline BRCA mutations. According to TCGA data, $14 \%$ of serous ovarian cancer had germline mutations and $6 \%$ had somatic mutation in $B R C A$. In Korea, the prevalence of germline mutations in $B R C A 1$ and BRCA2 is approximately $25 \%$ to $33 \%$ in those with a family history and approximately $10 \%$ in those without a family history. Therefore, personalized medicine based on genetic information including BRCA status is an important part of ovarian cancer treatment.

\section{Implementation of HPV vaccination: the Malaysian experience}

The implementation of HPV vaccination in low- or middleincome countries has encountered many hurdles, including that of cost. Malaysia was the first middle-income country in the world to implement a national HPV vaccination program 
in 2010. It is a school-based vaccination program targeting girls attending year seven in schools (13-year-old girls). Immunization in the clinic is proposed to 13-year-old out-of-school girls. This program was very successful as $95.9 \%$ and $97.9 \%$ of parents gave consent to their daughters to be vaccinated and $97.9 \%$ and $95.9 \%$ of girls who obtained parental consent completed all three courses of the vaccination in 2010 and 2011, respectively. In 2012, a catch-up vaccination program was introduced targeting girls aged 18 years. Suresh Kumarasamy suggested that the reasons for the success of this program included endorsement and recommendation by the medical profession, political will and leadership, the involvement of stakeholders early on in the program, predicting and managing potential risks, monitoring implementation closely, a good existing school health program, the involvement of the Ministry of Education, and giving sufficient information about the vaccine and its safety to parents.

\section{Surgery for early-stage cervical cancer: toward a less-radical strategy}

Radical hysterectomy has been used for the standard surgical management of early cervical cancer. All patients with early cervical cancer undergo radical surgery, which causes significant urinary and interstitial morbidity regardless of the extent of the disease. There is no high level of evidence regarding current surgical management of early cervical cancer. An effort to tailor the extent of surgery to the extent of early cervical cancer has been attempted recently. The guidelines for the surgical management of breast cancer are a good example. These guidelines were established based on results of clinical trials. In this lecture, clinical trials aiming at tailoring the extent of surgery to the extent of early cervical cancer were presented, along with a review of literature.

\section{Ovarian cancer screening}

In this lecture, the current status of ovarian cancer screening was presented and the future directions of ovarian cancer screening were reviewed and discussed. Ovarian cancer screening has two aims: the detection of early-stage disease and the differentiation of benign tumors from malignant ovarian tumors. Practical tools for ovarian cancer screening include screening for serum tumor markers and ultrasound imaging; however, data from recent, large-scale clinical trials do not support the use of these tools for the cost-effective screening of ovarian cancer. Multimodal screening may be beneficial in high-risk women and is recommended by professional groups. Algorithms using HE4 were found to be beneficial for discriminating benign from malignant ovarian tumors.

\section{SESSION 6. SURGERY FOR GYNECOLOGIC CANCER 2}

This session focused on minimally invasive surgery and fertility-preserving abdominal radical trachelectomy. These two approaches now dominate the surgical management of gynecologic cancers.

\section{Laparoscopic radical hysterectomy}

The adoption of laparoscopic surgery for the surgical management of cervical cancer has been slower than that of endometrial cancer because of the technical difficulties associated with laparoscopic surgery and the diversity of the approaches employed; however, recent improvements in laparoscopic instruments and surgical techniques have made laparoscopic radical hysterectomy the preferred surgical approach for the surgical management of early cervical cancer. Laparoscopic radical hysterectomy has better surgical outcomes than other methods without affecting survival outcomes or increasing the number of complications. In this lecture, the outcomes of laparoscopic radical hysterectomy were reviewed and the surgical technique of laparoscopic radical hysterectomy was shown in a surgical video. At earlier periods, the use of laparoscopic radical hysterectomy was limited to small cervical tumors $<2 \mathrm{~cm}[26,27]$; however, with the increase in surgical experience, the radicality of laparoscopic radical hysterectomy has become comparable to that of open radical hysterectomy [28]. Currently, the indication for radical hysterectomy has been extended to cervical tumors $>4 \mathrm{~cm}$ [29]. Recent studies suggest that the benefit of laparoscopic surgery extends to elderly and obese patients [30,31].

\section{Abdominal radical trachelectomy: where are we now?}

Vaginal radical trachelectomy is now an accepted treatment modality for the management of young women with early cervical cancer who wish to preserve their fertility; however, because of the limited surgical radicality and the long learning curve for vaginal radical trachelectomy, abdominal radical trachelectomy has been introduced to overcome these limitations. In this lecture, the experiences of Japanese doctors with abdominal radical trachelectomy were presented, together with a review of the literature.

\section{Laparoscopic surgery in early-stage ovarian cancer}

Laparotomy with a vertical midline abdominal incision has been the standard surgical procedure for the surgical staging of ovarian cancer. Over the last two decades, however, minimally invasive surgical techniques have dramatically improved the surgical management of ovarian cancer and have been frequently applied in this context, although many physicians 
continue to debate the use of laparoscopic surgery for ovarian cancer. Since Querleu and Leblanc $[32,33]$ first described laparoscopic surgical staging for ovarian cancer in 1994, many studies have reported the feasibility and safety of laparoscopic surgical staging [34-37]; however, there has never been a prospective randomized trial until now and the evidence for a role for laparoscopic surgery in the management of ovarian cancer is still insufficient [38]. Future prospective trials should help confirm the feasibility and safety of laparoscopic surgical staging in ovarian cancer.

\section{Robotic surgery in cervical cancer}

Robotic surgery is gaining popularity in the surgical management of gynecologic cancers. Although the cost of this type of surgery is the biggest hurdle preventing its popularity in Asian countries, it could become the dominant paradigm in the near future for the surgical management of gynecologic cancers. In this lecture, the status of robotic surgery for the management of gynecologic cancers and the surgical outcomes associated with this treatment modality were reviewed, and surgical techniques were presented in a video. Because robotic surgery has similar outcomes to laparoscopic surgery, but has several advantages over laparoscopic surgery, including a short learning curve, the use of robotic surgery is expected to continue to increase in the future.

\section{CONFLICT OF INTEREST}

No potential conflict of interest relevant to this article was reported.

\section{REFERENCES}

1. Vissink A, Mitchell JB, Baum BJ, Limesand KH, Jensen SB, Fox PC, et al. Clinical management of salivary gland hypofunction and xerostomia in head-and-neck cancer patients: successes and barriers. Int J Radiat Oncol Biol Phys 2010;78:983-91.

2. Mell LK, Mehrotra AK, Mundt AJ. Intensity-modulated radiation therapy use in the U.S., 2004. Cancer 2005;104:1296-303.

3. Westermann AM, Jones EL, Schem BC, van der Steen-Banasik EM, Koper P, Mella O, et al. First results of triple-modality treatment combining radiotherapy, chemotherapy, and hyperthermia for the treatment of patients with stage IIB, III, and IVA cervical carcinoma. Cancer 2005;104:763-70.

4. Kim SY, Hong YS, Kim DY, Kim TW, Kim JH, Im SA, et al. Preoperative chemoradiation with cetuximab, irinotecan, and capecitabine in patients with locally advanced resectable rectal cancer: a multicenter Phase II study. Int J Radiat Oncol Biol Phys 2011;81:677-
83.

5. Lim K, Small W Jr, Portelance L, Creutzberg C, Jurgenliemk-Schulz IM, Mundt A, et al. Consensus guidelines for delineation of clinical target volume for intensity-modulated pelvic radiotherapy for the definitive treatment of cervix cancer. Int J Radiat Oncol Biol Phys 2011;79:348-55.

6. Mundt AJ, Lujan AE, Rotmensch J, Waggoner SE, Yamada SD, Fleming $G$, et al. Intensity-modulated whole pelvic radiotherapy in women with gynecologic malignancies. Int J Radiat Oncol Biol Phys 2002;52:1330-7.

7. Chen MF, Tseng CJ, Tseng CC, Kuo YC, Yu CY, Chen WC. Clinical outcome in posthysterectomy cervical cancer patients treated with concurrent Cisplatin and intensity-modulated pelvic radiotherapy: comparison with conventional radiotherapy. Int J Radiat Oncol Biol Phys 2007;67:1438-44.

8. Kidd EA, Siegel BA, Dehdashti F, Rader JS, Mutic S, Mutch DG, et al. Clinical outcomes of definitive intensity-modulated radiation therapy with fluorodeoxyglucose-positron emission tomography simulation in patients with locally advanced cervical cancer. Int J Radiat Oncol Biol Phys 2010;77:1085-91.

9. Gandhi AK, Sharma DN, Rath GK, Julka PK, Subramani V, Sharma S, et al. Early clinical outcomes and toxicity of intensity modulated versus conventional pelvic radiation therapy for locally advanced cervix carcinoma: a prospective randomized study. Int J Radiat Oncol Biol Phys 2013;87:542-8.

10. Plante M, Renaud MC, Francois H, Roy M. Vaginal radical trachelectomy: an oncologically safe fertility-preserving surgery. An updated series of 72 cases and review of the literature. Gynecol Oncol 2004;94:614-23.

11. Dargent D, Franzosi F, Ansquer $Y$, Martin X, Mathevet $P$, Adeline P. Extended trachelectomy relapse: plea for patient involvement in the medical decision. Bull Cancer 2002;89:1027-30.

12. Saso S, Ghaem-Maghami S, Chatterjee J, Naji O, Farthing A, Mason $P$, et al. Abdominal radical trachelectomy in West London. BJOG 2012;119:187-93.

13. Li J, Wu X, Li X, Ju X. Abdominal radical trachelectomy: is it safe for IB1 cervical cancer with tumors $\geq 2$ cm? Gynecol Oncol 2013;131: 87-92.

14. Lintner B, Saso S, Tarnai L, Novak Z, Palfalvi L, Del Priore G, et al. Use of abdominal radical trachelectomy to treat cervical cancer greater than $2 \mathrm{~cm}$ in diameter. Int J Gynecol Cancer 2013;23:1065-70.

15. Wethington SL, Sonoda Y, Park KJ, Alektiar KM, Tew WP, Chi DS, et al. Expanding the indications for radical trachelectomy: a report on 29 patients with stage IB1 tumors measuring 2 to 4 centimeters. Int J Gynecol Cancer 2013;23:1092-8.

16. Gallos ID, Yap J, Rajkhowa M, Luesley DM, Coomarasamy A, Gupta $J K$. Regression, relapse, and live birth rates with fertility-sparing therapy for endometrial cancer and atypical complex endometrial hyperplasia: a systematic review and metaanalysis. Am J Obstet Gynecol 2012;207:266.e1-12.

17. Park JY, Kim DY, Kim JH, Kim YM, Kim KR, Kim YT, et al. Long-term oncologic outcomes after fertility-sparing management using oral progestin for young women with endometrial cancer (KGOG 
2002). Eur J Cancer 2013:49:868-74.

18. Park JY, Seong SJ, Kim TJ, Kim JW, Kim SM, Bae DS, et al. Pregnancy outcomes after fertility-sparing management in young women with early endometrial cancer. Obstet Gynecol 2013;121:136-42.

19. Park JY, Kim DY, Kim TJ, Kim JW, Kim JH, Kim YM, et al. Hormonal therapy for women with stage IA endometrial cancer of all grades. Obstet Gynecol 2013;122:7-14.

20. Park JY, Lee SH, Seong SJ, Kim DY, Kim TJ, Kim JW, et al. Progestin retreatment in patients with recurrent endometrial adenocarcinoma after successful fertility-sparing management using progestin. Gynecol Oncol 2013;129:7-11.

21. Nam JH, Park JY. Fertility-sparing surgery for young women with early-stage epithelial ovarian cancer. Gynecol Obstet Invest 2013; 76:14-24.

22. Kajiyama H. Fertility sparing surgery in patients with early stage epithelial ovarian cancer: implication of survival analysis and lymphadenectomy. J Gynecol Oncol 2014;25:270-1.

23. Mitamura T, Watari H, Todo Y, Kato T, Konno Y, Hosaka M, et al. Lymphadenectomy can be omitted for low-risk endometrial cancer based on preoperative assessments. J Gynecol Oncol 2014;25:301-5.

24. Chang SJ, Bristow RE. Evolution of surgical treatment paradigms for advanced-stage ovarian cancer: redefining 'optimal' residual disease. Gynecol Oncol 2012;125:483-92.

25. Westin SN, Rallapalli V, Fellman B, Urbauer DL, Pal N, Frumovitz $\mathrm{MM}$, et al. Overall survival after pelvic exenteration for gynecologic malignancy. Gynecol Oncol 2014;134:546-51.

26. Nam JH, Kim JH, Kim DY, Kim MK, Yoo HJ, Kim YM, et al. Comparative study of laparoscopico-vaginal radical hysterectomy and abdominal radical hysterectomy in patients with early cervical cancer. Gynecol Oncol 2004;92:277-83.

27. Nam JH, Park JY, Kim DY, Kim JH, Kim YM, Kim YT. Laparoscopic versus open radical hysterectomy in early-stage cervical cancer: long-term survival outcomes in a matched cohort study. Ann Oncol 2012;23:903-11.
28. Park JY, Nam JH. Laparotomy conversion rate of laparoscopic radical hysterectomy for early-stage cervical cancer in a consecutive series without case selection. Ann Surg Oncol 2014;21:3030-5.

29. Park JY, Kim DY, Kim JH, Kim YM, Kim YT, Nam JH. Laparoscopic versus open radical hysterectomy in patients with stage IB2 and IIA2 cervical cancer. J Surg Oncol 2013;108:63-9.

30. Park JY, Kim DY, Kim JH, Kim YM, Kim YT, Nam JH. Laparoscopic versus open radical hysterectomy for elderly patients with earlystage cervical cancer. Am J Obstet Gynecol 2012;207:195.e1-8.

31. Park JY, Kim DY, Kim JH, Kim YM, Kim YT, Nam JH. Laparoscopic compared with open radical hysterectomy in obese women with early-stage cervical cancer. Obstet Gynecol 2012;119:1201-9.

32. Querleu D, LeBlanc E. Laparoscopic infrarenal paraaortic lymph node dissection for restaging of carcinoma of the ovary or fallopian tube. Cancer 1994;73:1467-71.

33. Querleu D. Laparoscopic surgical therapy and staging in a case of early malignant granulosa cell tumor of the ovary. Eur J Obstet Gynecol Reprod Biol 1994;54:215-7.

34. Park HJ, Kim DW, Yim GW, Nam EJ, Kim S, Kim YT. Staging laparoscopy for the management of early-stage ovarian cancer: a metaanalysis. Am J Obstet Gynecol 2013;209:58.e1-8.

35. Ditto A, Martinelli F, Lorusso D, Haeusler E, Carcangiu M, Raspagliesi F. Fertility sparing surgery in early stage epithelial ovarian cancer. J Gynecol Oncol 2014;25:320-7.

36. Aoki D. Laparoscopic surgery for early ovarian cancer. J Gyneco Oncol 2014;25:168-9.

37. Koo YJ, Kim JE, Kim YH, Hahn HS, Lee IH, Kim TJ, et al. Comparison of laparoscopy and laparotomy for the management of early-stage ovarian cancer: surgical and oncological outcomes. J Gynecol Oncol 2014;25:111-7.

38. Lawrie TA, Medeiros LR, Rosa DD, da Rosa MI, Edelweiss MI, Stein AT, et al. Laparoscopy versus laparotomy for FIGO stage I ovarian cancer. Cochrane Database Syst Rev 2013;2:CD005344. 
Supplementary 1. Program of the 3rd ASGO International Workshop on Gynecolgic Oncology

Date: 23 (Sat) - 24 (Sun) August, 2014 Venue: Asan Medical Center, Conference Hall (B1)

\begin{tabular}{|c|c|c|}
\hline Day 1 & 23 August, 2014 (Saturday) & \\
\hline \multirow[t]{2}{*}{ 08:45-09:00 } & Opening remark & Joo-Hyun Nam, President of ASGO \\
\hline & Congratulatory remark & Toshiharu Kamura, Immediate past president of ASGO \\
\hline 09:00-09:25 & Updates in cervical cancer prevention and control & Hextan YS Ngan (Hong Kong) \\
\hline 09:25-09:50 & Tailored radiation therapy: IMRT / Proton therapy & Won Park (Korea) \\
\hline 09:50-10:15 & The evolution of treatment methods for cervical cancer in China & Zeyi Cao (China) \\
\hline $10: 45-11: 10$ & Fertility preservation in cervical cancer & Xiaohua Wu (China) \\
\hline $11: 10-11: 35$ & Fertility preservation in endometrial cancer & Jeong-Yeol Park (Korea) \\
\hline \multirow[t]{2}{*}{$11: 35-12: 00$} & Fertility preservation in ovarian cancer & Woong Ju (Korea) \\
\hline & Luncheon seminar (Supported by Janssen Korea) & Chair: Se-Jun Han (Korea) \\
\hline $12: 00-12: 20$ & $\begin{array}{l}\text { Role of pegylated liposomal doxorubicin in recurrent } \\
\text { ovarian cancer }\end{array}$ & Soo-Young Hur (Korea) \\
\hline $12: 20-13: 30$ & Lunch & \\
\hline $15: 10-15: 40$ & Break & \\
\hline Session IV & Recent advances in translational research & $\begin{array}{l}\text { Chair: Efrén Domingo (Philippines), } \\
\text { Seung Cheol Kim (Korea) }\end{array}$ \\
\hline 15:40-16:05 & An addition to biomarkers for epithelial ovarian cancer & Jae-Hoon Kim (Korea) \\
\hline 16:05-16:30 & The cancer genome atlas: TCGA data mining & Chi-Heum Cho (Korea) \\
\hline $16: 30-16: 55$ & MicroRNA strategy in ovarian cancer & Keun Ho Lee (Korea) \\
\hline $16: 55-17: 20$ & $\begin{array}{l}\text { Patient-derived tumor xenograft (AVATAR) model for } \\
\text { gynecologic cancer }\end{array}$ & Jeong-Won Lee (Korea) \\
\hline 18:00 & Welcome Dinner & \\
\hline
\end{tabular}




\begin{tabular}{|c|c|c|}
\hline Day 2 & 24 August, 2014 (Sunday) & \\
\hline Time & Titles & Chair/Speaker \\
\hline Session V & $\begin{array}{l}\text { Special issues II: Updates in the management of gynecologic } \\
\text { cancers }\end{array}$ & Chair: Ikuo Konishi (Japan), Soon-Do Cha (Korea) \\
\hline 09:00-09:25 & HPV vaccination: the Malaysian experience & Suresh Kumarasamy (Malaysia) \\
\hline 09:25-09:50 & $\begin{array}{l}\text { Surgery for early stage cervical cancer: } \\
\text { toward less-aggressive way }\end{array}$ & Jae-Weon Kim (Korea) \\
\hline 09:50-10:15 & Ovarian cancer screening & Sarikapan Wilailak (Thailand) \\
\hline 10:15-10:40 & $\begin{array}{l}\text { Current practice for selecting and testing ovarian cancer } \\
\text { patients for BRCA mutation }\end{array}$ & Byeong-Gie Kim (Korea) \\
\hline 10:40-11:00 & Break & \\
\hline Session VI & Surgery for gynecologic cancer (II) & $\begin{array}{l}\text { Chair: Mohamad Farid Aziz (Indonesia), } \\
\text { Kimio Ushijima (Japan) }\end{array}$ \\
\hline 11:00-11:25 & Laparoscopic radical hysterectomy & Joo-Hyun Nam (Korea)/Dae-Yeon Kim (Korea) \\
\hline $11: 25-11: 50$ & Abdominal radical trachelectomy: where are we now? & Ikuo Konishi (Japan) \\
\hline 11:50-12:15 & Laparoscopic surgery in early stage ovarian cancer & Jae-Kwan Lee (Korea) \\
\hline $12: 15-12: 40$ & Robotic surgery in cervical cancer & Kung-Liahng Wang (Taiwan) \\
\hline $12: 40-14: 00$ & Lunch & \\
\hline Session VII & Medical writing \& reviewing & Chair: Yin Nin Chia (Singapore), Young Tae Kim (Korea) \\
\hline $14: 00-14: 20$ & Common mistakes by Asian medical writers & Masao Okazaki (USA) \\
\hline 14:20-14:40 & Manuscript preparation before submitting to the JGO & Sokbom Kang (Korea) \\
\hline 14:40-15:00 & What do the editors expect of the reviewers? & Chul-Min Lee (Korea) \\
\hline 15:00-15:20 & Closing remark & $\begin{array}{l}\text { Hee-Sug Ryu, } \\
\text { Congress President of the } 4 \text { th Biennial Meeting of ASGO }\end{array}$ \\
\hline
\end{tabular}




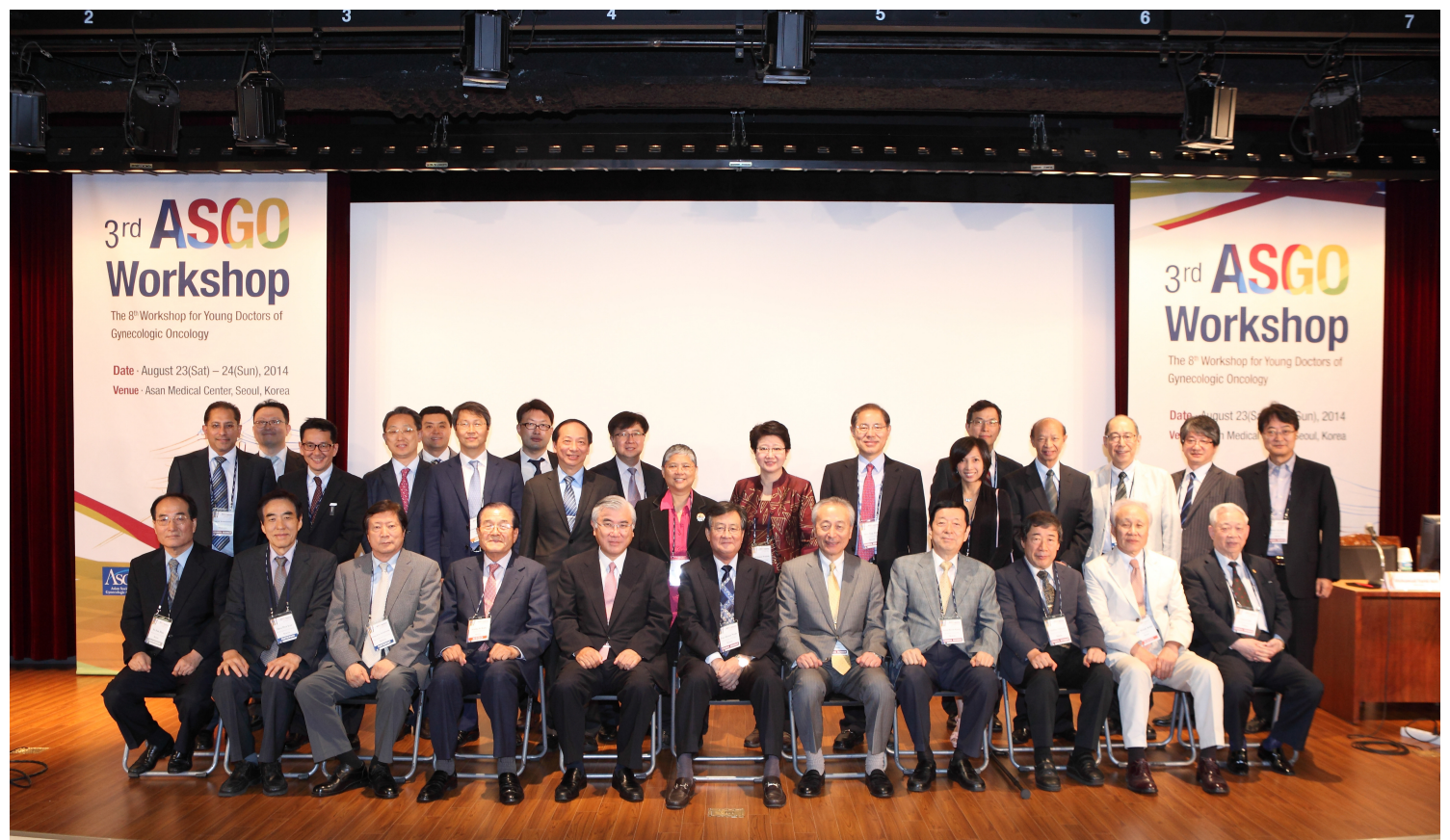

Supplementary 2. Counsil members of ASGO, speakers, and chairpersons of the 3rd ASGO workshop.

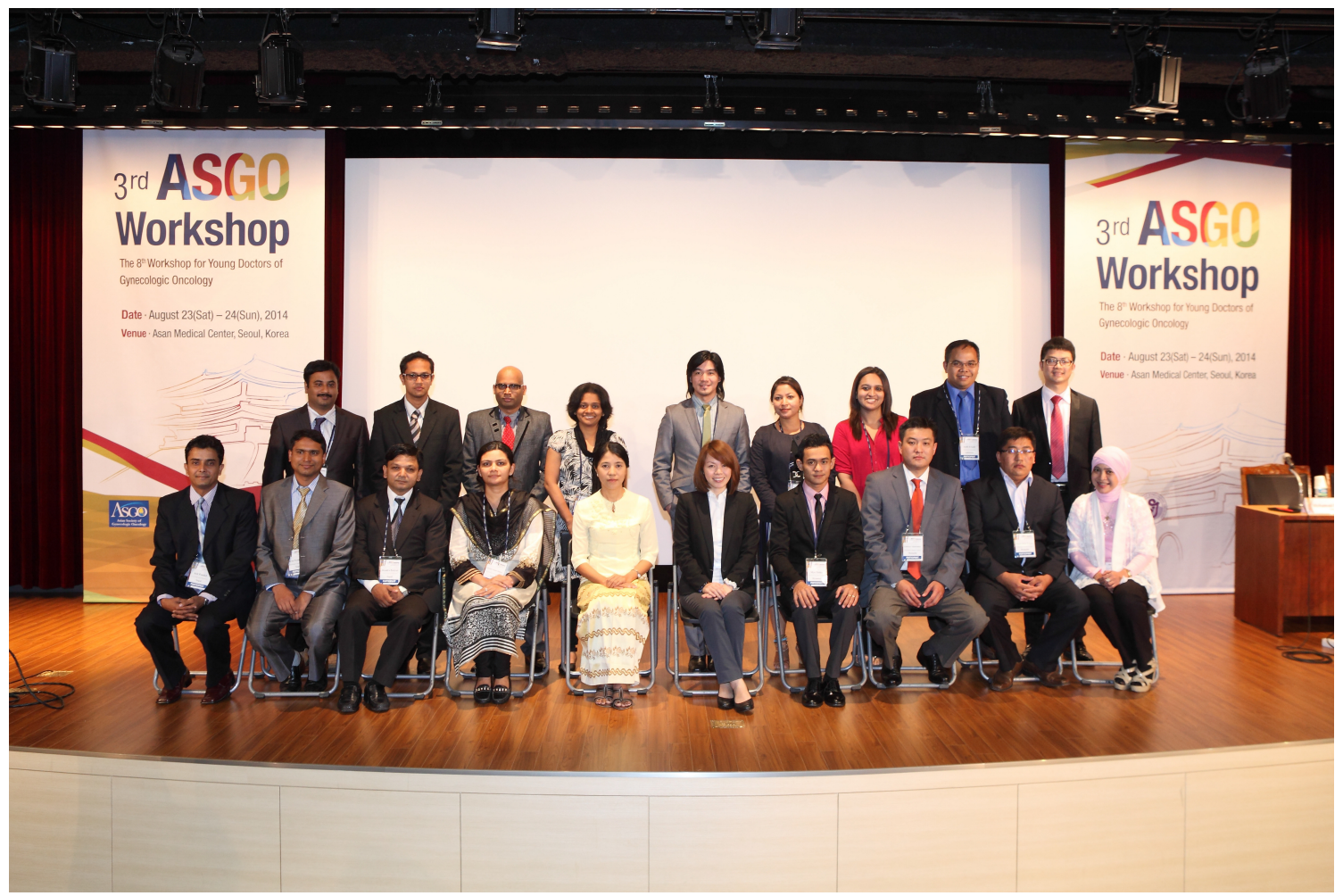

Supplementary 3. Young docters who gained travel award to participate the 3rd ASGO workshop. 